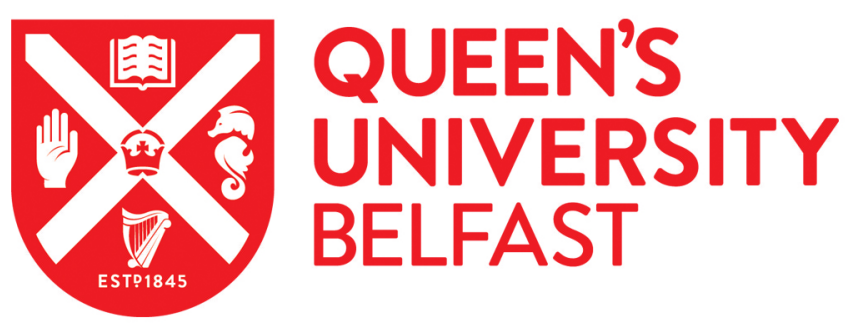

\title{
Effect of poly ethylene glycol on the mechanical and thermal properties of bioactive Poly ( $\varepsilon$-caprolactone) melt extrudates for pharmaceutical applications
}

Douglas, P., Albadarin, A. B., Sajjia, M., Mangwandi, C., Kuhs, M., Collins, M. N., \& Walker, G. M. (2016). Effect of poly ethylene glycol on the mechanical and thermal properties of bioactive Poly ( $\varepsilon$-caprolactone) melt extrudates for pharmaceutical applications. International Journal of Pharmaceutics.

https://doi.org/10.1016/j.ijpharm.2016.01.036

\section{Published in:}

International Journal of Pharmaceutics

\section{Document Version:}

Peer reviewed version

Queen's University Belfast - Research Portal:

Link to publication record in Queen's University Belfast Research Portal

\section{Publisher rights}

(c) 2016 Elsevier Ltd. This manuscript version is made available under the CC-BY-NC-ND 4.0 license http://creativecommons.org/licenses/bync-nd/4.0/ which permits distribution and reproduction for non-commercial purposes, provided the author and source are cited.

\section{General rights}

Copyright for the publications made accessible via the Queen's University Belfast Research Portal is retained by the author(s) and / or other copyright owners and it is a condition of accessing these publications that users recognise and abide by the legal requirements associated with these rights.

Take down policy

The Research Portal is Queen's institutional repository that provides access to Queen's research output. Every effort has been made to ensure that content in the Research Portal does not infringe any person's rights, or applicable UK laws. If you discover content in the Research Portal that you believe breaches copyright or violates any law, please contact openaccess@qub.ac.uk. 


\title{
Effect of poly ethylene glycol on the mechanical and thermal properties of bioactive Poly (E-caprolactone) melt extrudates for pharmaceutical applications
}

\author{
P. Douglas ${ }^{1}$, Ahmad B. Albadarin ${ }^{1,2^{*}}$, Mustafa Sajjia ${ }^{3}$, Chirangano Mangwandi ${ }^{1}$, \\ Manuel Kuhs ${ }^{2}$, Maurice N. Collins ${ }^{4}$, Gavin M. Walker ${ }^{1,2,3}$ \\ ${ }^{1}$ School of Chemistry and Chemical Engineering, Queen's University Belfast, \\ Belfast BT9 5AG, Northern Ireland, UK. \\ ${ }^{2}$ Solid State Pharmaceutical Centre, Bernal Institute, Department of Chemical and Environmental Sciences, \\ University of Limerick, Ireland \\ ${ }^{3}$ Pharmaceutical Manufacturing Technology Centre, Bernal Institute, Department of Chemical and \\ Environmental Sciences, University of Limerick, Ireland \\ ${ }^{4}$ Stokes Laboratories, Bernal Institute, University of Limerick, Ireland.
}

\begin{abstract}
:
This paper investigates the effects of polyethylene glycol (PEG), on the mechanical and thermal properties of nalidixic acid/ploy $\varepsilon$-caprolactone (NA)/PCL blends prepared by hot melt extrusion. The blends were characterized by tensile and flexural analysis, dynamic mechanical analysis, differential scanning calorimetry, thermogravimetric analysis and X-ray diffraction. Experimental data indicated that the addition of NA caused loss of the tensile strength and toughness of PCL. Thermal analysis of the PCL showed that on addition of the thermally unstable NA, thermal degradation occurred early and was autocatalytic. However, the NA did benefit from the heat shielding provided by the PCL matrix resulting in more thermally stable NA particles. Results show that loading PEG in the PCL had a detrimental effect on the tensile strength and toughness of the blends, reducing them by $20-40 \%$. The partial miscibility of the PCL-PEG system, causes an increase in $\mathrm{T} g$. While increases in the crystallinity is attributed to the plasticisation effect of PEG and the nucleation effect of NA. The average crystal size increased by $8 \%$ upon PEG addition.
\end{abstract}

Keywords: Mechanical and Thermal Properties; Melt Extrusion; Drug Formulation; Polycaprolactone; Nalidixic Acid.

*Corresponding author: Dr Ahmad B. Albadarin: Ahmad.B.Albadarin@ul.ie. Tel: +44 746080 5982; fax: +353 (0) 61202568 . 


\section{INTRODUCTION}

Aliphatic polyesters such as poly (butylene succinate), poly(L-lactic acid) (PLLA) and Poly ( $\varepsilon$-caprolactone) (PCL) have extensive range of degradation rates and mechanical properties, unsuitable stiffness and/or degradation rates limit their application [1-3]. Consequently, plasticisation through blending with other polymers or through copolymerization is often employed to adjust the mechanical and thermal properties of these polymers in accordance to application requirements [4].

PCL blends have properties that are attractive for the design of tunable biomaterials such as slow crystallisation kinetics and low melting temperatures in the physiological range. Also, slow degradation rates, with relatively minimal acid generation, can be valuable for prolonged drug release. Furthermore, its exceptional blend-compatibility has stimulated wide research into its potential application in the biomedical field [5]. PCL blends/compounds are used in sutures, ultra-thin films for dressing cutaneous wounds [6], contraceptive and fixation devices [7, 8], dentistry as root fillings [9] and pharmaceutical applications for manufacturing polymeric devices for controlled drug delivery [10]. Dosage formulations for drug delivery have received excessive attention as they can transfer drugs, genes and proteins via various administration routes, including intravenous, ocular, nasal and oral [11]. A previous study has focused on controlling the release profile of a model active pharmaceutical ingredient (API), the antibacterial nalidixic acid (NA), from PCL by blending with PEG [10]. The rate of in vitro release of NA from the extrudate was shown to be strongly influenced by the composition and processing properties of the blends. The mechanical and thermal characterisation of new polymeric systems is necessary to clarify the micro-structure of heterogeneous systems, such as semi-crystalline polymers, blends or copolymers, especially for controlled drug delivery. However, there are only very few publications studying the influence of conditions and processing procedures on the final mechanical and thermal properties of the system [12]. We 
have already reported our investigation of the effect of PLLA addition on the thermomechanical properties of PCL/NA blends [11]; here we report on the effect of PEG on the mechanical and thermal properties of PCL/NA blends as prepared by hot melt extrusion. PEG is approved by FDA for use in medical devices, it is commonly used for PEGylation and it can transfer its properties to other molecules by covalent bonding, which can result in toxic molecules becoming non-toxic and hydrophobic molecules becoming soluble at certain ratios $[13,14]$. The PEG was chosen in this study as the blended material in order to reduce the stiffness of the PCL and to increase thermal degradation rates with the overall goal of aiding the release of drugs from the PCL matrix. Once all the blends were processed using extrusion and pressed into plaques, analysis of the resultant material was undertaken, with mechanical and thermal properties determined. The blends were characterized by tensile and flexural analysis, Dynamic Mechanical Analysis (DMA), Differential Scanning Calorimetry (DSC), Thermogravimetric Analysis (TGA) and X-ray Diffraction (XRD).

\section{MATERIALS \& EXPERIMENTAL PROCEDURES}

\subsection{Poly ( $\varepsilon$-caprolactone), Polyethylene glycol and Nalidixic Acid}

Full details regarding the polymers physical properties and reason of selection can be found in $[10,11]$. NA's chemical formula is $\mathrm{C}_{12} \mathrm{H}_{12} \mathrm{~N}_{2} \mathrm{O}_{3}$ and is chemically known as 1,4-dihydro-1ethyl-7-methyl-4-oxo-1,8-naphthridine-3-carboxylic acid. PEG was selected as a pore former to aid drug release. All \% compositions are w/w.

\subsection{Sample preparation}

The methods of preparing the polymer blends are given in a previous publication [10]. In brief; PCL, PEG and NA mixtures with different compositions were blended into their respective compositions in a high speed mixer at $1800 \pm 5 \mathrm{rpm}$ for $5 \mathrm{~min}$ (Rondol DAC150, UK). Material

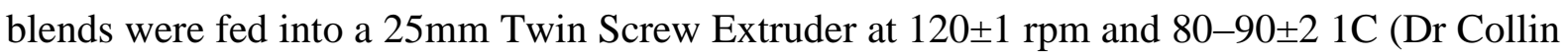


Z25, Germany), to produce a continuous strand of each blend. The strands were then quenched in a water bath $(20 \pm 0.5 \mathrm{C})$, and finally passed through a pelletiser.

\subsection{Characterisation}

The method used for tensile and flexural analysis, dynamic mechanical thermal analysis, DSC, TGA and wide angle XRD is identical to that described in $[10,11]$.

\section{RESULTS AND DISCUSSION}

\subsection{Mechanical Properties}

\subsubsection{Tensile Properties}

The tensile properties of the PCL-PEG blends are shown in Figures 1-3. The loading of PEG in the PCL matrix to $25 \%(\mathrm{w} / \mathrm{w})$ has a detrimental effect on the tensile strength and toughness of the blends, reducing them by $20-40 \%$. At lower concentrations of PEG (i.e. 5\%) there is little change in any of the tensile properties, though with the addition of the 5\% NA a decrease is evident in the tensile strength and toughness of the materials (see Figure 1). Figures 2 and 3 show the effect of PEG and NA on the stiffness of the blends, there are competing mechanisms influencing the blend stiffness the PEG appears to reduce the stiffness while the NA acts a reinforcement which increases stiffness. Rosa and co-workers found similar results using low molecular weight PEG which was added to PCL. Their studies showed that the PEG decreased the tensile strength and elongation at break respectively [15]. In Figure 3, the addition of the PEG has little effect on the flexural modulus of the PCL matrix while the addition of NA into the 5\% PEG blend greatly increases the degree of stiffness. However, this stiffness is counterbalanced by the increased loading of PEG to $25 \%$, thereby restoring flexibility.

\subsubsection{Dynamic mechanical thermal analysis}

The mechanical transitions from the crystallisation of PCL-PEG blends are shown in Figure 4A and Figure 4B. The data again indicates that the $\beta$ and $\alpha$ transitions are observed but it is clear that the addition of the PEG to the PCL reduces the $\beta$ transition. The results indicate that 
the storage modulus decreases as the testing temperature is increased and drops sharply at the glass transition temperature where there is a corresponding large peak in the $\tan \delta$. The small change in the peak $\alpha$ transition and also in the $\mathrm{T} g$ can be attributed to the partial miscibility of the PCL-PEG system, which causes the increase towards the PEG $\mathrm{T} g$ of $-24^{\circ} \mathrm{C}$ as the weight content increases [16]. Again, the stiffening effect of the NA is noted by the increasing storage modulus values recorded at ambient conditions.

\subsection{Thermal Properties}

\subsubsection{Differential Scanning Calorimetry}

PCL, which is semi crystalline, has a low melting point $\left(58-64{ }^{\circ} \mathrm{C}\right.$ depending on crystal content) and glass transition temperature $\left(-60^{\circ} \mathrm{C}\right)$. It can be processed using standard thermoplastic processing techniques for example injection moulding or extrusion [10].

\subsubsection{Non isothermal DSC}

Scan rates of 2 and $100 \mathrm{C} / \mathrm{min}$ were used to study the melting and crystallisation properties of the PCL-PEG blends. Tables 3 and 4 detail the changes in melt temperature, degree of crystallinity and crystallisation temperature associated with the PEG in the PCL matrix for the differing scan rates. As expected, little change is noted in the melting temperature in Figure 5A; however the degree of crystallinity (see $\Delta \mathrm{H}_{\mathrm{m}}$ theoretical in Table 3) of PCL increased with the addition of the PEG and showed further increase with the addition of NA. This increase in crystallinity is a result of the plasticisation effect of PEG and the nucleation effect of NA. The shape of the melting curve is typical for crystallite reorganisation [4], but on the addition of NA to the $25 \%$ PEG system, the melting curve displays a shoulder due to the formation of two crystal populations typically associated with polymer blends [17] with $\mathrm{Tc}=40.1$ and $34.7^{\circ} \mathrm{C}$ for PEG and PCL, respectively. PEG undergoes melting in the same temperature range as PCL but crystallises just below that of PCL, therefore it is likely that the mobile PEG chains act as sites for PCL crystal growth, resulting in heterogeneous nucleation. Coupled with this, the 
increase in crystallisation temperature (given in Table 2) for the blends when the PEG and NA are loaded brings about more refinement in the PCL crystals as seen in the narrowing of the melting width [5]. The $2 \mathrm{C} / \mathrm{min}$ scan rate gives the impression that both the PCL and PEG are miscible blends as shown in Figure 5B. In order to determine the separation of the PCL-PEG crystals, extra blends containing $1 \%$ and $70 \%(\mathrm{w} / \mathrm{w})$ PEG were made for comparative purposes with the standard blends. Only one crystallisation peak can be determined at concentrations less than 25\% PEG (Figure 5B). Only at very high concentrations could the separation of the PCL-PEG crystals be determined (70\% PEG trace). Therefore, although not entirely conclusive, it is assumed that at low concentrations the PEG has no effect on the overall degree of PCL crystallisation and all enthalpies of fusion are treated as solely belonging to PCL. This method was also adopted by An et al in their work on PCL-PEG copolymers[18]. Table 2 shows the thermal data obtained for the PCL-PEG blends at a scan rate of $100 \mathrm{C} / \mathrm{min}$. At this faster rate, data are more unreliable due to the thermal lag in the system which in this case results in increased Tm and decreased Tc in the region of $20{ }^{\circ} \mathrm{C}$ for the PCL moiety and a Tc decrease of $40{ }^{\circ} \mathrm{C}$ for the PEG moiety. However this inaccuracy is compensated by the ability of this analysis to separate out crystallisation peaks as shown in Figure 6. The above discussion can be summarised showing the major differences in the scan rates for the blends in Figure 7. The cooling peak at $\sim 22{ }^{\circ} \mathrm{C}$ is assigned to PCL, as the energy required to form crystals is associated with a higher temperature and the higher molecular weight of the PCL imparts more crystal stability, thus producing more perfect PCL crystals [19]. Therefore the PEG cooling occurs at the lower temperature of $\sim 0^{\circ} \mathrm{C}$, due to its smaller molecular weight and lower enthalpy of crystallisation

\subsubsection{Isothermal crystallisation}

The isothermal crystallisation of the PCL-PEG blends was studied at $38^{\circ} \mathrm{C}$ over a 40 minute period. The temperature of $38^{\circ} \mathrm{C}$ was chosen since above this temperature melting begins. This 
analysis produces a long scan and crystallisation time, as crystal formation is no longer rate controlled. Figure 8 and Table 3 illustrate the isothermal behaviour of the PCL-PEG blends. The addition of the PEG into the system has a detrimental effect on the enthalpy of fusion of the blends. However, addition of NA (acting as a nucleating agent) increases the crystallinity again, though this increase is counteracted by the increased loading of the PEG. The total time of crystallisation is reduced with the addition of the PEG and NA, thereby increasing the rate of crystallisation at $38^{\circ} \mathrm{C}$.

\subsubsection{Thermogravimetric Analysis}

Ramping the blends to a maximum temperature of $500{ }^{\circ} \mathrm{C}$ produced the degradation curves shown in Figure 9. The onset for the thermal degradation of PCL and virgin PEG was determined from the graph to be approximately 400 and $370{ }^{\circ} \mathrm{C}$, respectively, similar to those of [20]. The addition of PEG to PCL even in small amounts caused a notable decrease in the degradation temperature, resulting in a $10{ }^{\circ} \mathrm{C}$ decrease with $25 \%$ PEG. The addition of PEG into the blends causes an expected decrease in the onset of thermal decomposition temperature, with the decrease being proportional to the amount of PEG present. This is attributed to ease of main chain movement and decomposition. The addition of NA into the blends at $5 \%$ shows a small restoration of the PCL degradation temperature, probably due to a reduction in chain mobility. The thermal stability of the blends over the 100 minute period at $200{ }^{\circ} \mathrm{C}$ is shown in Figure 10. The bulk polymers had good thermal stability throughout the experiment, losing $\sim 2 \%$ of their weight. This is attributed to trapped water molecules or volatiles within the matrix [21]. However, the addition of PEG caused a consistent $1 \%$ increase in the thermal stability over the entire scan period, thereby indicating a small but synergistic thermal stability of the combined polymers. This thermal stability is still present even with the addition of NA with increased PEG weight fraction, while the onset of NA degradation remains unchanged at $~ 30$ minutes [10]. In terms of PCL shielding of NA, this is slightly weakened by the introduction 
of PEG into the matrix, as seen in Figure 11. Over the first 30 minute period before the degradation of the NA, the rate of volatiles/water expulsion can be seen to be greater with the PEG blend, and this can be attributed to the low molecular weight of PEG which allows the incorporation of more $\mathrm{OH}$ groups which are hydrophilic.

\subsubsection{Wide Angle X-Ray Diffraction}

WAXS was carried out on the PCL-PEG blends to determine the interaction between the crystal phases of both materials. Analysing the data in Figures 12A and 12B confirms some degree of interaction between the phases. The major crystal peaks of pure PCL at 21.26, 21.86 and 23.57 $2 \theta$ are present in all blends unaltered, with new peaks at $2 \theta=19.12,23.28$ and 26.97 due to the presence of PEG. Combination peaks in the XRD trace are visible in Figure 12B. The peaks at 18.4 and 27.04 are those of the PEG crystals indicating a mix of polymer crystals within the XRD sample. The small peak at $2 \theta=11.81$ occurs with the addition of the NA. Therefore no new peaks are formed for the blends of PCL and PEG, which indicates immiscibility between the polymers [15], thus supporting the mechanical data. With the addition of PEG the average crystal size increased by $8 \%$, with no further increases evident with increasing loading. This crystallite size is not to be confused with crystal size which is measured using optical microscopy. As there are both size and strain broadening of the XRD peak, the strain broadening can be assumed to remain unchanged with the addition of PEG in PCL. Therefore it is probable that no new defects in the crystal lattice or widening of the crystal size range occur [14].

\section{CONCLUSIONS}

The mechanical performance of the blends is complex with the involvement of competing mechanisms of stiffing induced by NA and plasticisation induced by PEG. The addition of PEG to PCL even in small amounts caused a notable decrease in the degradation temperature, crystallinity, time of crystallisation and the average crystal size increased. PEG also contributed 
to a consistent improvement in the thermal stability of the blends. Both additives had little influence on PCL's melting and crystallisation temperatures. However, on addition of the thermally unstable NA, thermal degradation of PCL occurred earlier and was autocatalytic. NA did benefit from the heat shielding provided by the PCL matrix resulting in more thermally stable NA particles. NA had a nucleating effect on PCL crystallinity, as determined using DSC and confirmed by XRD analysis. The accretion of PCL crystals with NA addition was also observed, as the PCL crystal size increased. A similar result was noted with the PCL-PEG blends.

\section{REFERENCES}

[1] Z. Qi, H. Ye, J. Xu, J. Chen, B. Guo, Improved the thermal and mechanical properties of poly(butylene succinate-co-butylene adipate) by forming nanocomposites with attapulgite, Colloids and Surfaces A: Physicochemical and Engineering Aspects 421 (2013) 109-117.

[2] S. Modi, K. Koelling, Y. Vodovotz, Assessing the mechanical, phase inversion, and rheological properties of poly-[(R)-3-hydroxybutyrate-co-(R)-3-hydroxyvalerate] (PHBV) blended with poly-(l-lactic acid) (PLA), European Polymer Journal 49 (2013) 3681-3690.

[3] Y. Bai, C. Jiang, Q. Wang, T. Wang, A novel high mechanical strength shape memory polymer based on ethyl cellulose and polycaprolactone, Carbohydrate Polymers 96 (2013) 522527.

[4] D. Barron, C. Birkinshaw, M.N. Collins, Reflection effects during the radiation sterilization of ultra high molecular weight polyethylene for total knee replacements, Journal of the Mechanical Behavior of Biomedical Materials 48 (2015) 46-50.

[5] E. Dalton, M.N. Collins, Lamella alignment ratio: a SAXS analysis technique for macromolecules, Journal of Applied Crystallography 47 (2014) 847-851.

[6] K.W. Ng, H.N. Achuth, S. Moochhala, T.C. Lim, D.W. Hutmacher, In vivo evaluation of an ultra-thin polycaprolactone film as awound dressing, Journal of Biomaterials Science Polymer Edition 18 (2007) 925-938.

[7] H. Sun, L. Mei, C. Song, X. Cui, P. Wang, The in vivo degradation, absorption and excretion of PCL-based implant., Biomaterials 27 (2006) 1735-1740.

[8] L. Onal, S. Cozien-Cazuc, I.A. Jones, C.D. Rudd, Water absorption properties of phosphate glass fiber-reinforced poly-epsilon-caprolactone composites for craniofacial bone repair, Journal of Applied Polymer Science 107 (2008) 3750-3755.

[9] A. Alani, J.C. Knowles, W. Chrzanowski, Y.-L. Ng, K. Gulabivala, Ion release characteristics, precipitate formation and sealing ability of a phosphate glasspolycaprolactone-based composite for use as a root canal obturation material, Dental Materials 25 (2009) 400-410.

[10] P. Douglas, G. Andrews, D. Jones, G. Walker, Analysis of in vitro drug dissolution from PCL melt extrusion, Chemical Engineering Journal 164 (2010) 359-370. 
[11] P. Douglas, A.B. Albadarin, A.a.H. Al-Muhtaseb, C. Mangwandi, G.M. Walker, Thermomechanical properties of poly $\varepsilon$-caprolactone/poly 1-lactic acid blends: Addition of nalidixic acid and polyethylene glycol additives, Journal of the Mechanical Behavior of Biomedical Materials 45 (2015) 154-165.

[12] Palchesko R.N., Zhang L., Sun Y., F. A.W., Development of polydimethylsiloxane substrates with tunable elastic modulus to study cell mechanobiology in muscle and nerve, PLoS ONE 7 (2012) e51499. doi:51410.51371/journal.pone.0051499.

[13] M. Zacchigna, G. Di Luca, V. Maurich, E. Boccù, Syntheses, chemical and enzymatic stability of new poly(ethylene glycol)-acyclovir prodrugs, Il Farmaco 57 (2002) 207-214.

[14] J. Milton-Harris, Poly(ethylene glycol) Chemistry, Biotechnical and Biomedical Applications 1st Edition, Springer (1992).

[15] D.S. Rosa, C.G.F. Guedes, F. Casarin, F.C. Bragança, The effect of the Mw of PEG in PCL/CA blends, Polymer Testing 24 (2005) 542-548.

[16] C.W. Nies, G.L. Messing, Effect of Glass-Transition Temperature of Polyethylene GlycolPlasticized Polyvinyl Alcohol on Granule Compaction, Journal of the American Ceramic Society 67 (1984) 301-304.

[17] S. Li, X. Chen, R. Gross, S. McCarthy, Hydrolytic degradation of PCL/PEO copolymers in alkaline media, Journal of Materials Science: Materials in Medicine 11 (2000) 227-233.

[18] J.H. An, H.S. Kim, J. Chung, D.S. Lee, Thermal behaviour of poly(e-caprolactone)poly(ethylene glycol)-poly(e-caprolactone) tri-block copolymers, Journal of Materials Science 36 (2001) 715-722.

[19] K. Cho, F. Li, J. Choi, Crystallization and melting behavior of polypropylene and maleated polypropylene blends, Polymer 40 (1999) 1719-1729.

[20] W.-C. Lai, W.-B. Liau, Thermo-oxidative degradation of poly(ethylene glycol)/poly(1lactic acid) blends, Polymer 44 (2003) 8103-8109.

[21] G. Sivalingam, G. Madras, Thermal degradation of binary physical mixtures and copolymers of poly( $\varepsilon$-caprolactone), poly(d, 1-lactide), poly(glycolide), Polymer Degradation and Stability 84 (2004) 393-398. 


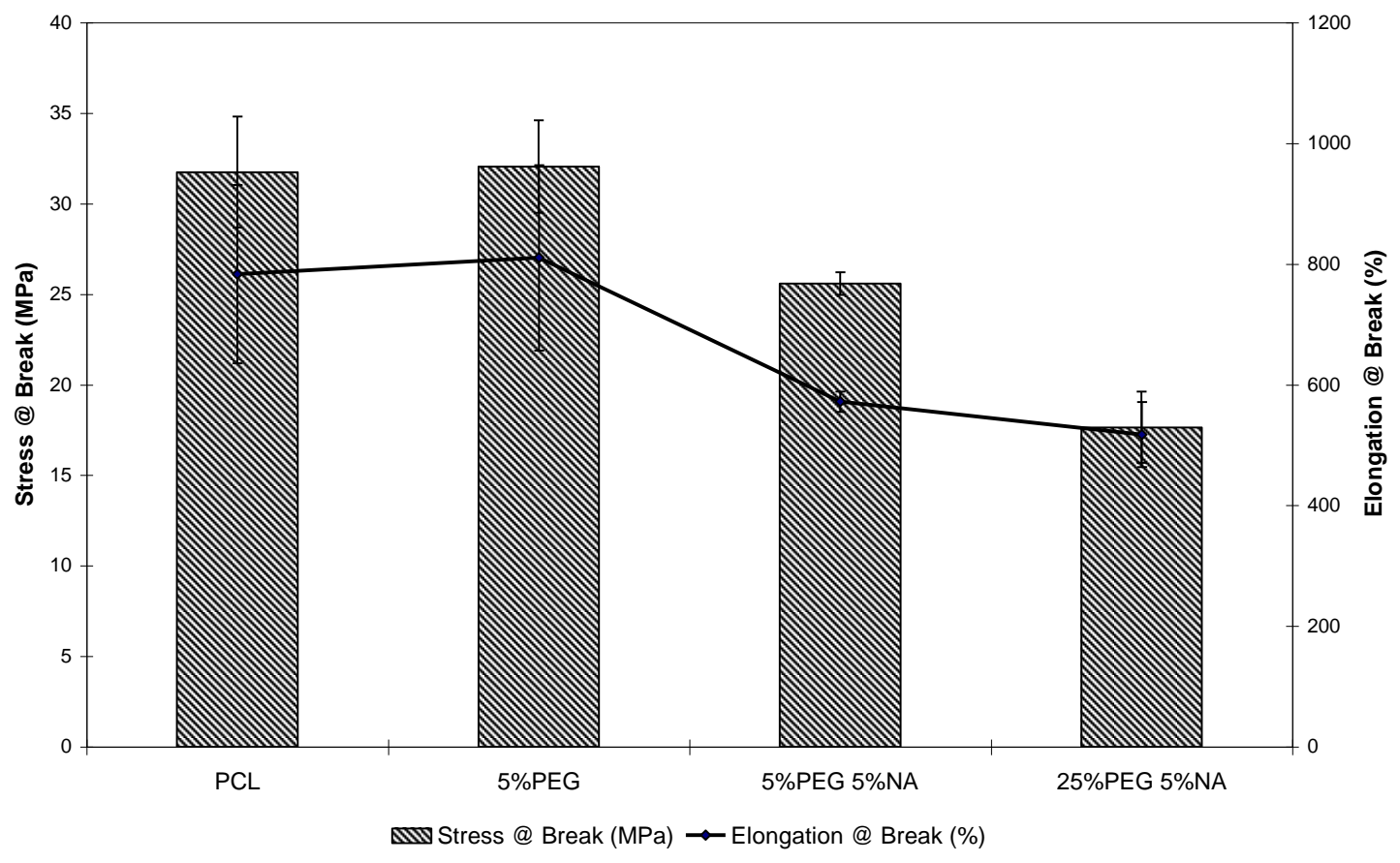

Figure 1: Tensile strength and Elongation at break of PCL-PEG blends.

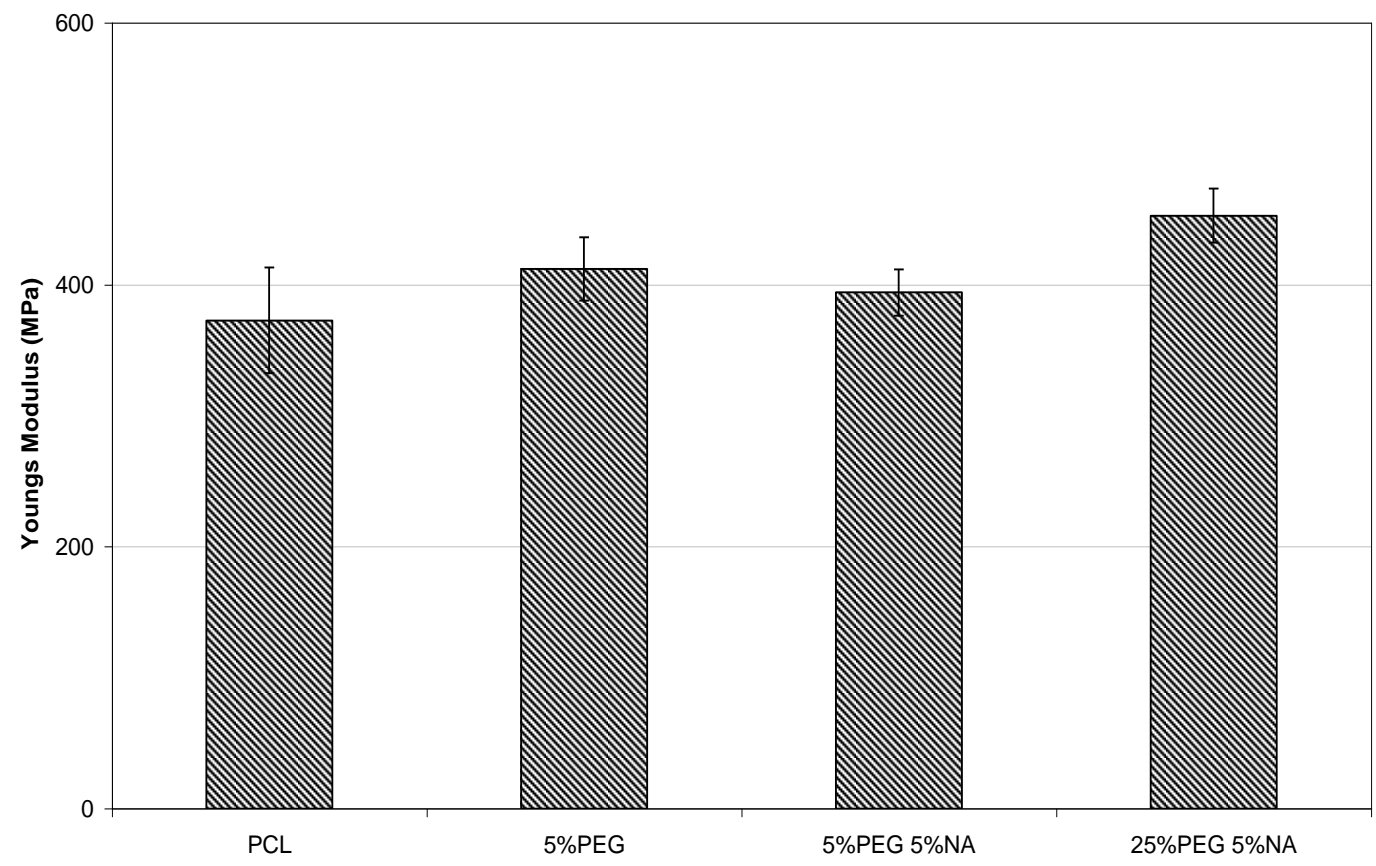

Figure 2: Young's modulus of PCL-PEG blends. 


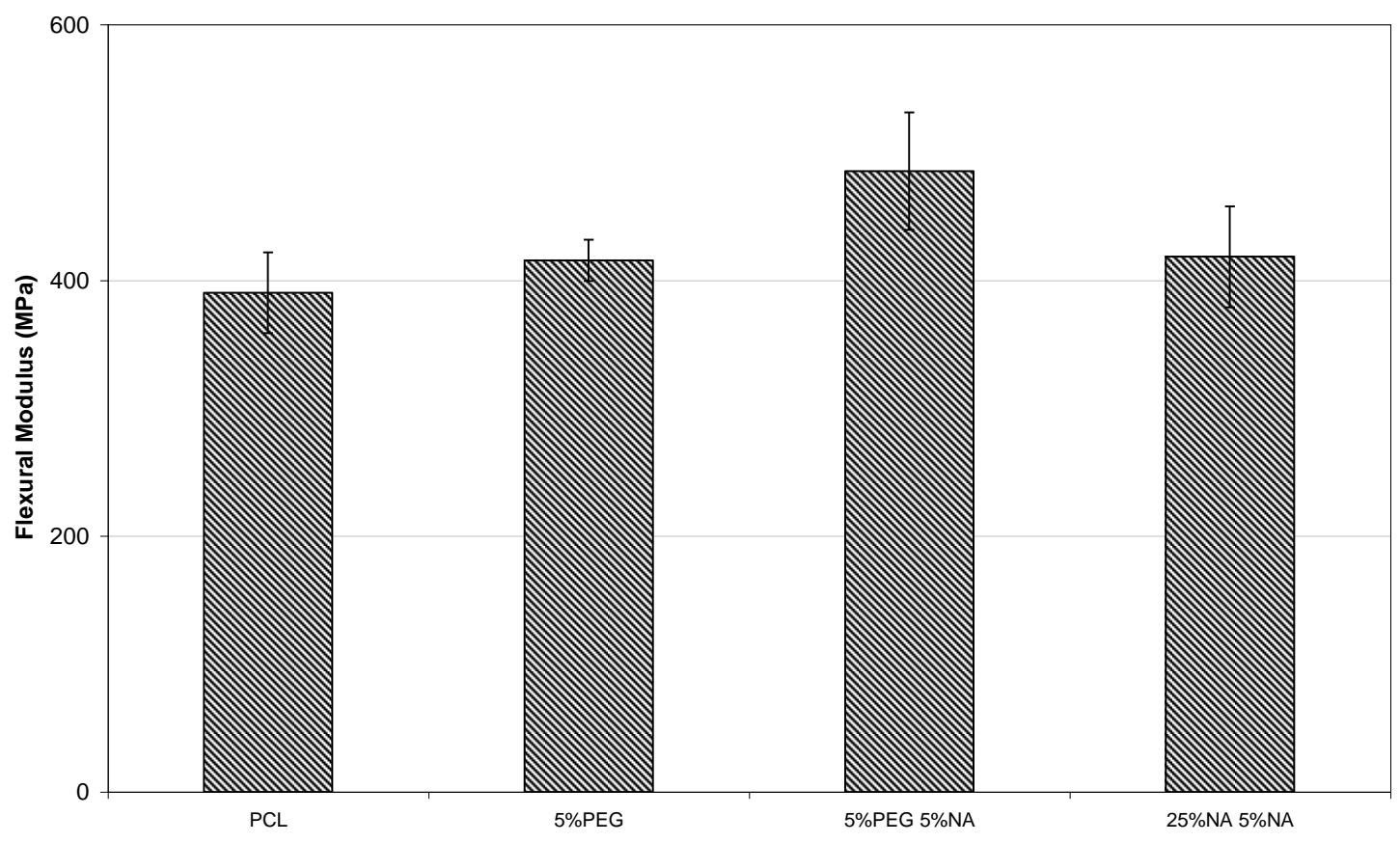

Figure 3: Flexural modulus of PCL-PEG blends. 

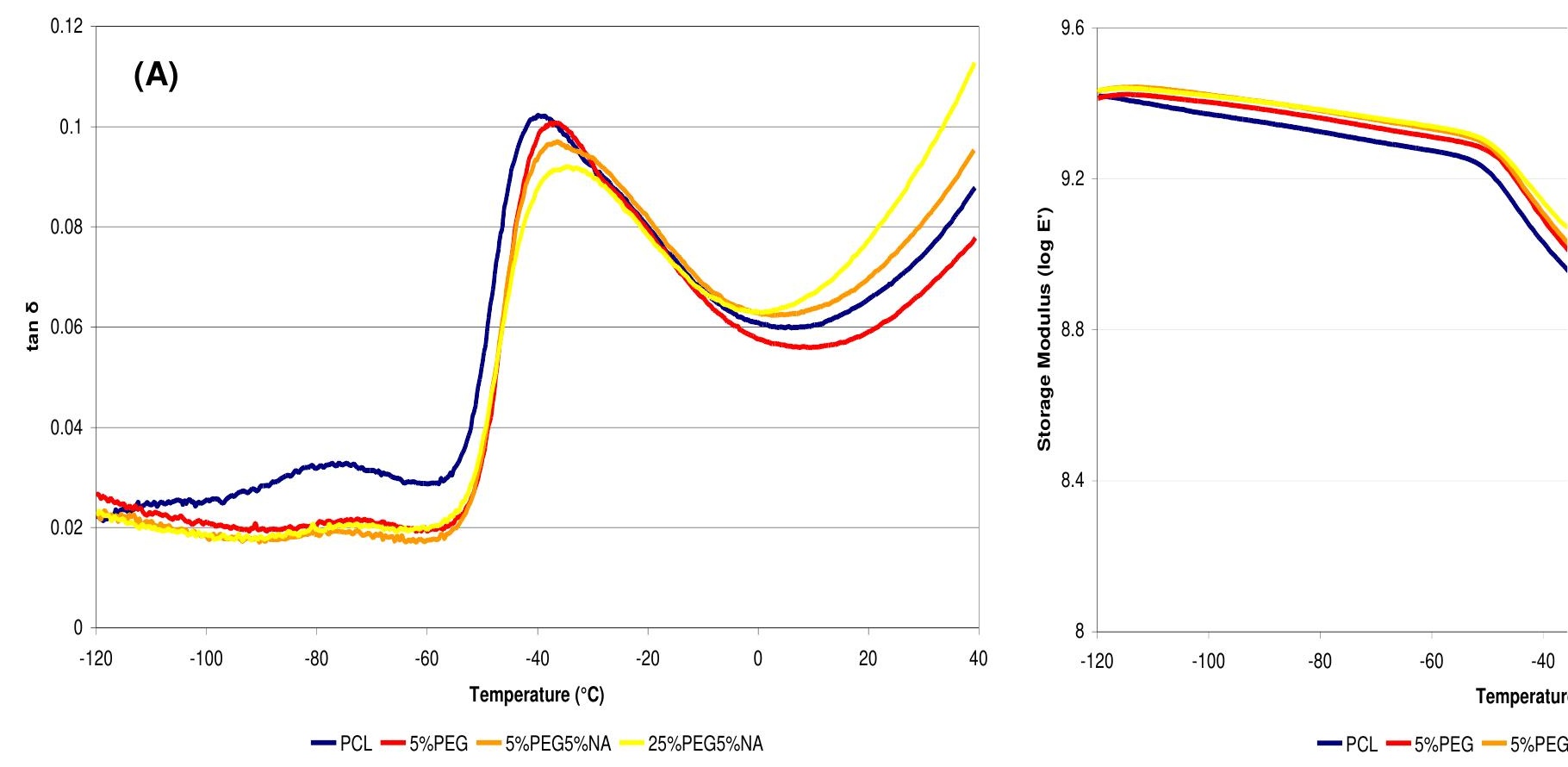

Figure 4: (A) Tan $\delta$ temperature sweeps for PCL-PEG blends and (B) Storage Modulus for PCL-PEG blends. 

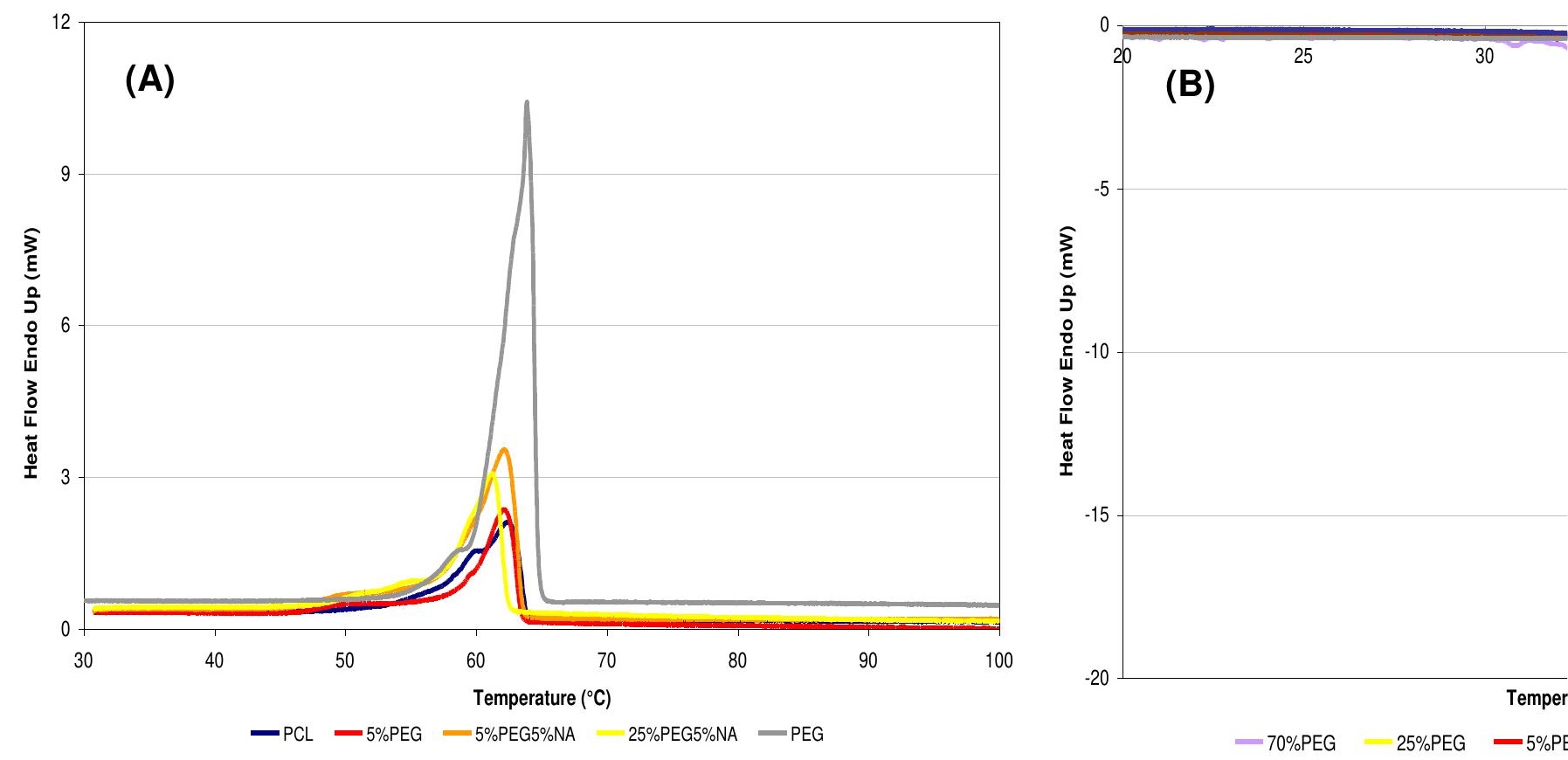

Figure 5: (A) Heating scans of the PCL-PEG blends and (B) Separation of PCL-PEG crystals at $2 \mathrm{degC} / \mathrm{min}$.

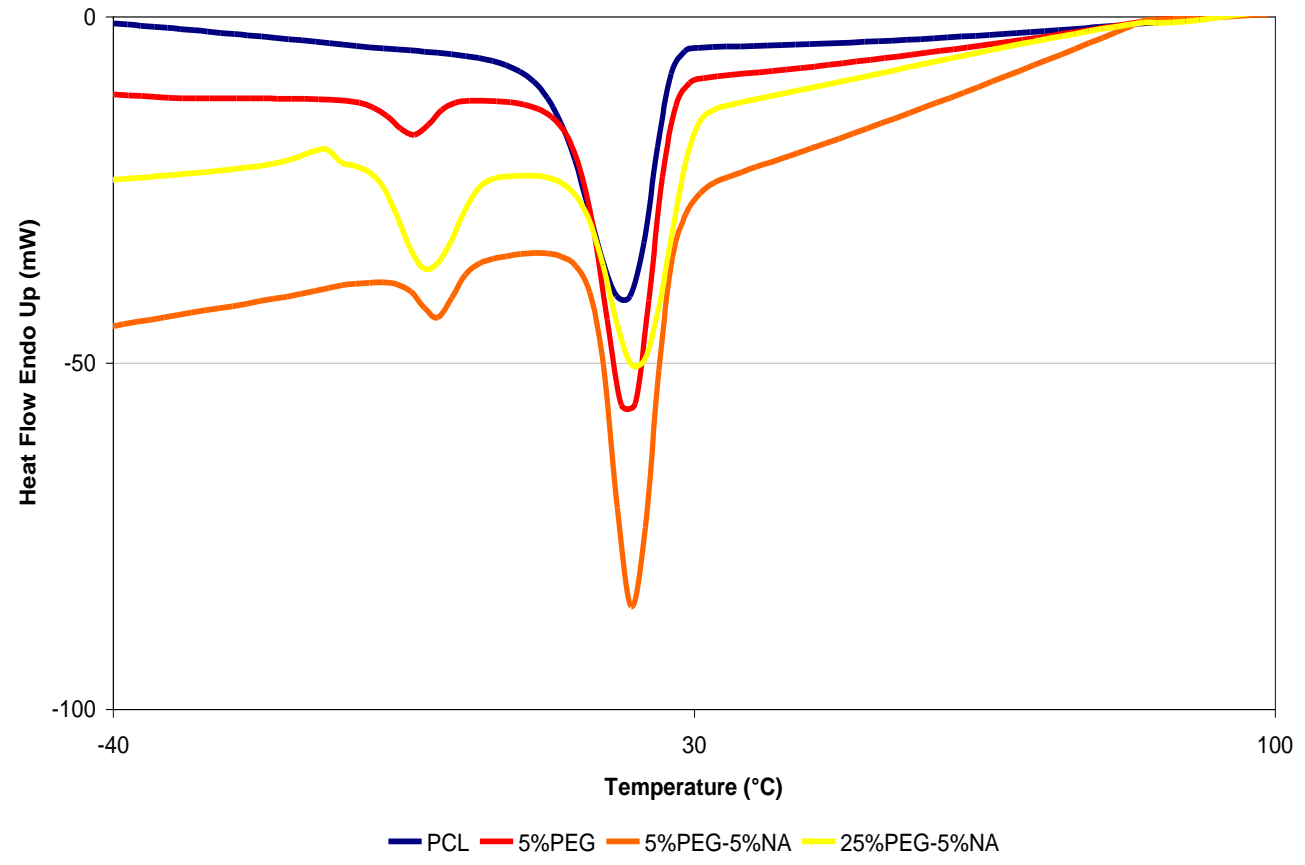


Figure 6: Separation of PCL and PEG at $100 \mathrm{degC} / \mathrm{min}$.

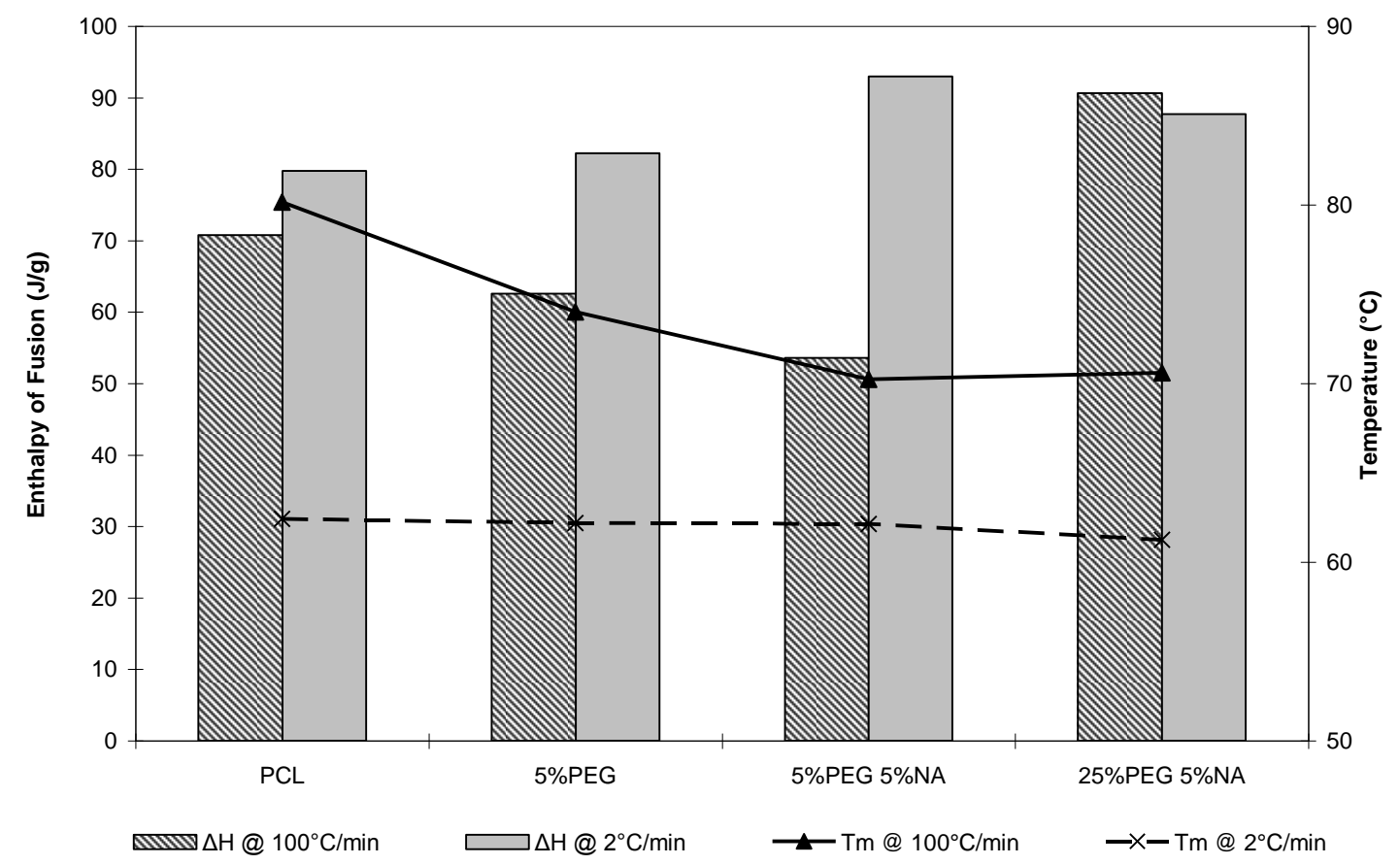

Figure 7: Scan rate differences in PCL-PEG blends.

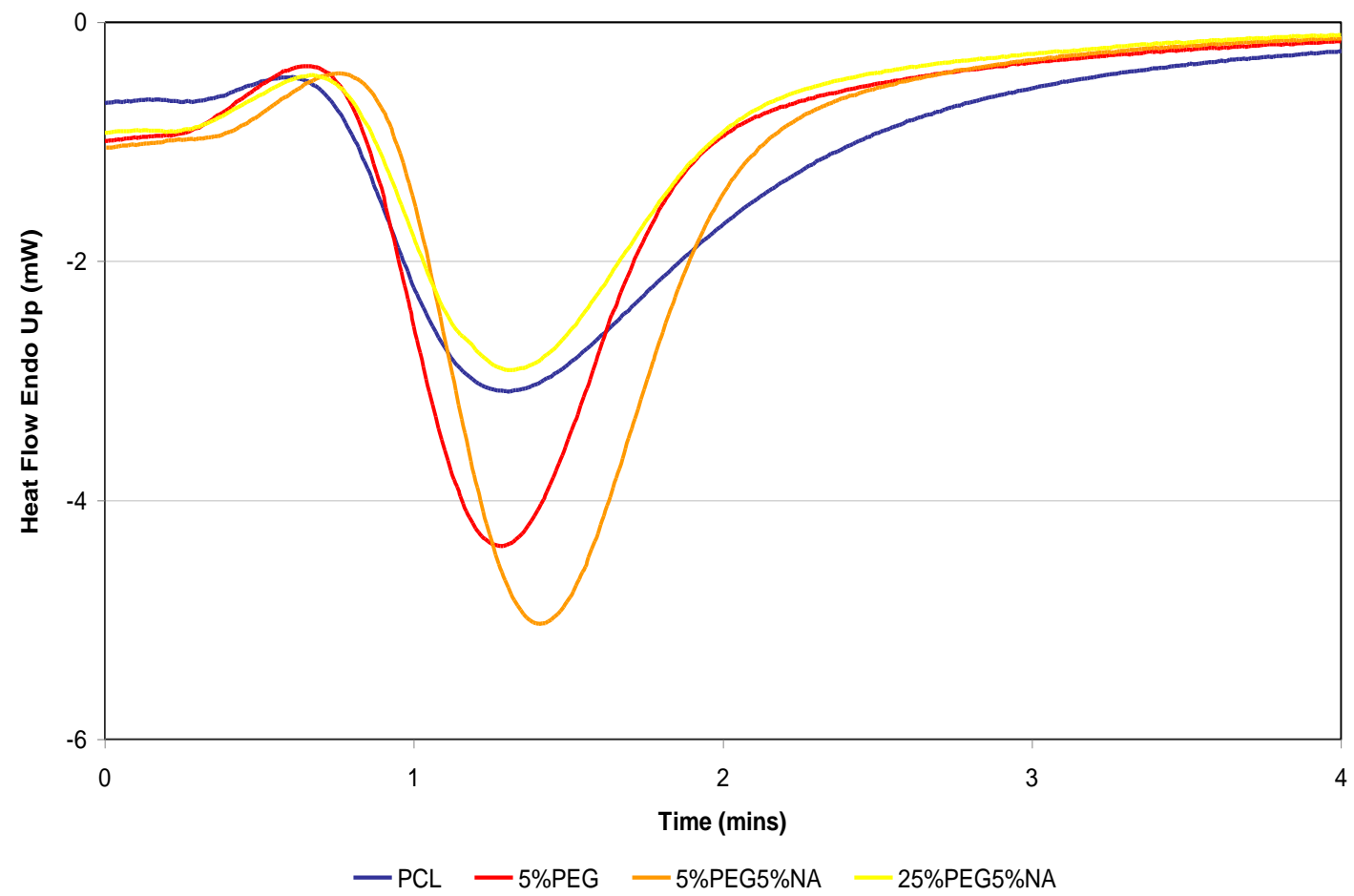

Figure 8: Isothermal scan for PCL-PEG blends. 


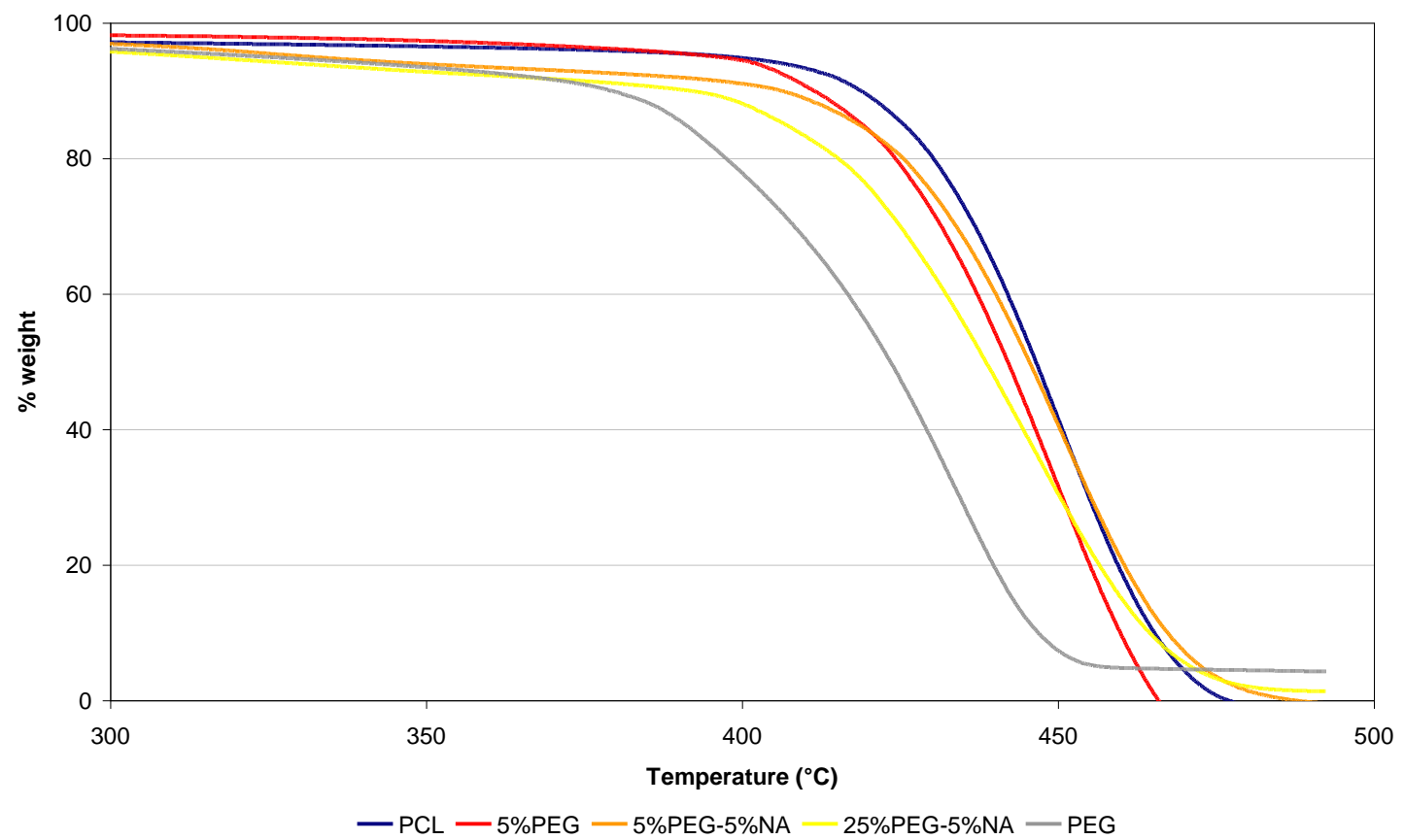

Figure 9: Thermal decomposition of PCL-PEG blends.

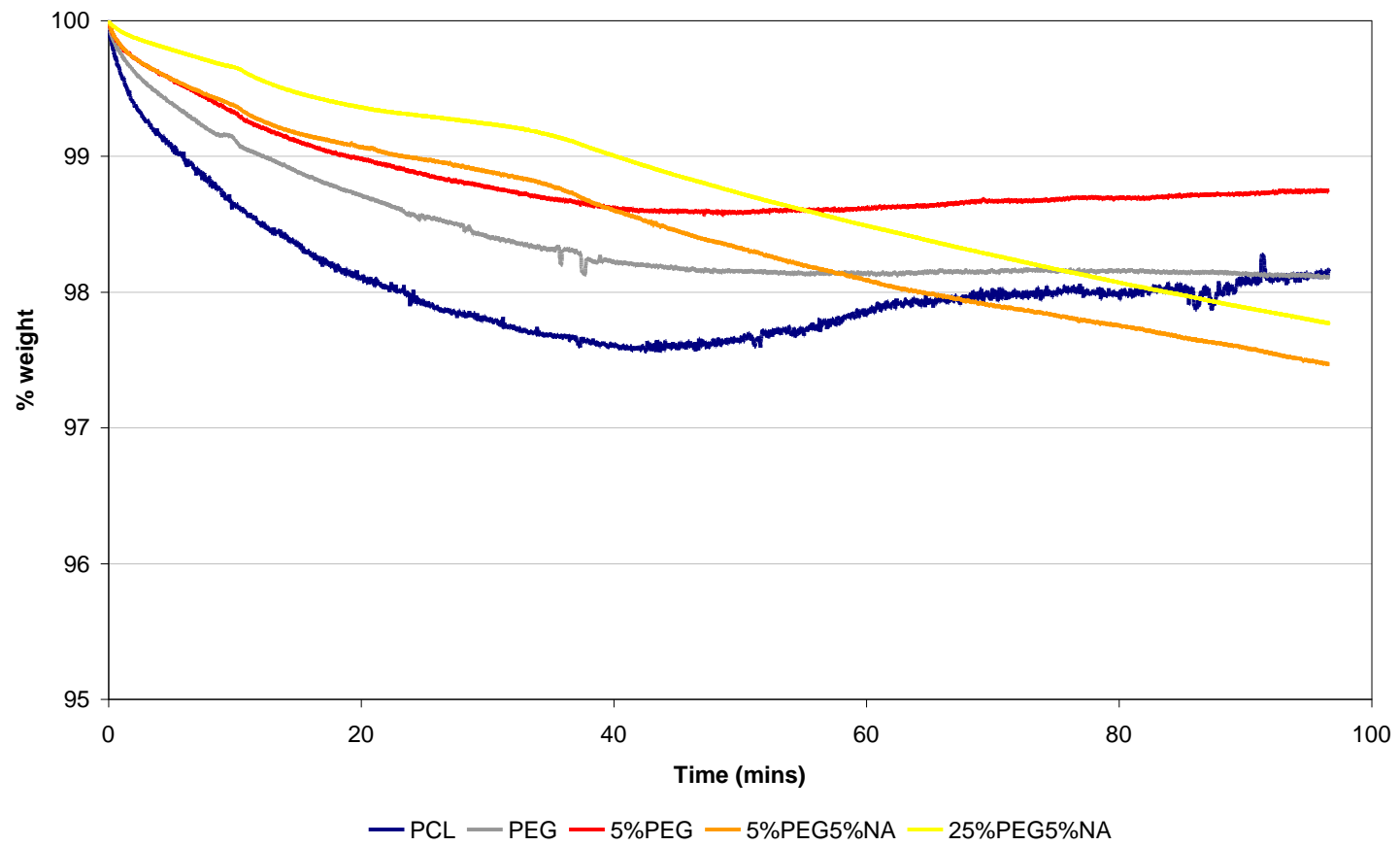

Figure 10: Isothermal degradation of PCL-PEG blends. 


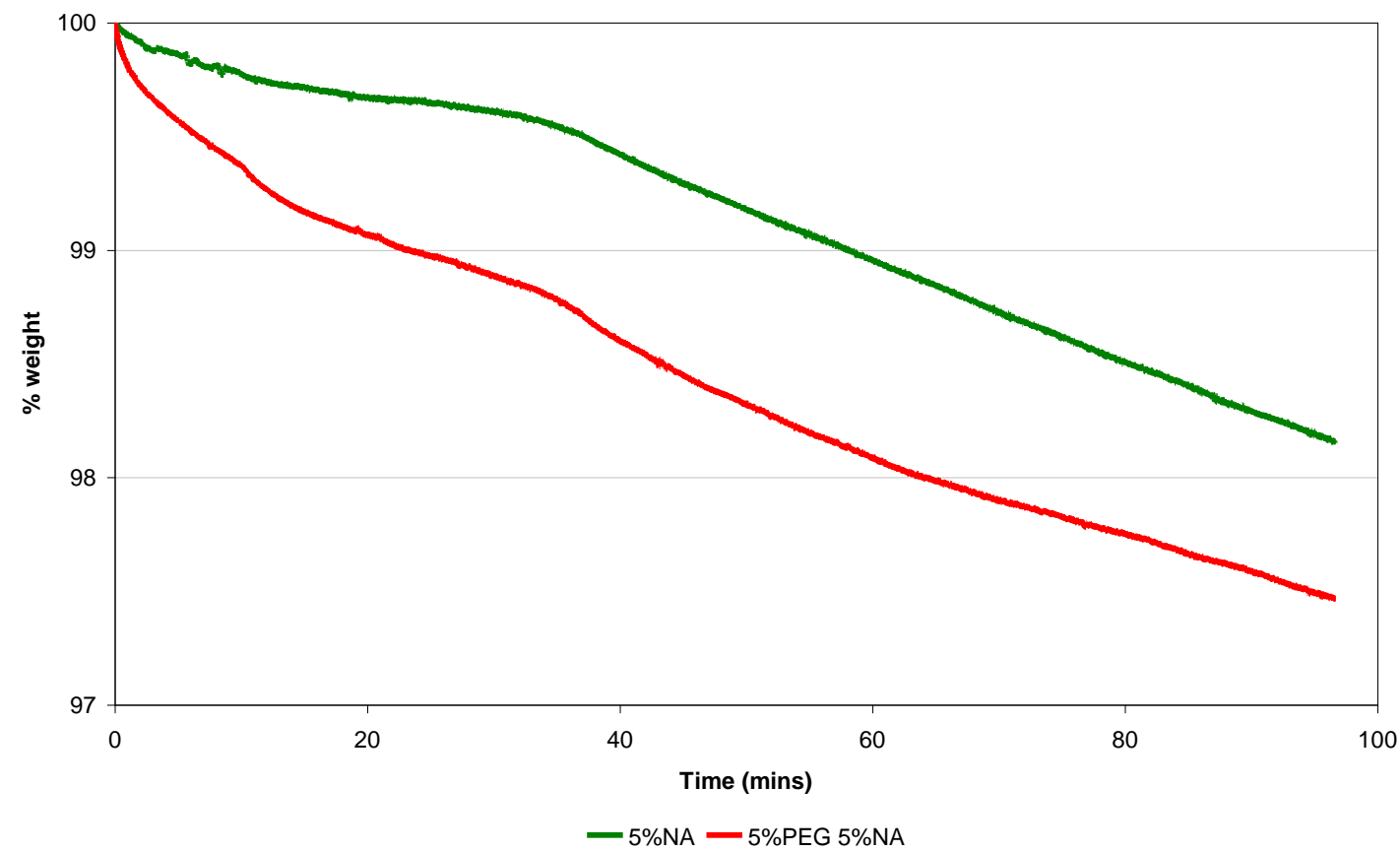

Figure 11: Effect of PEG on PCL-5\%NA. 


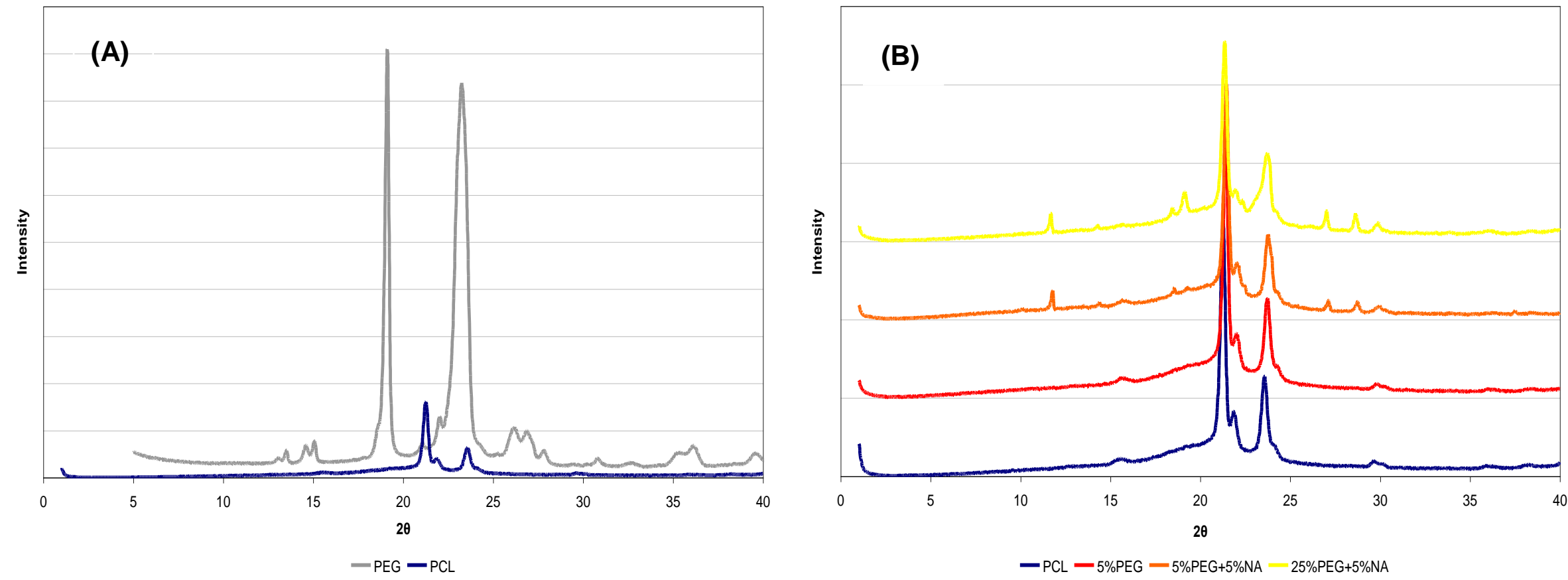

Figure 12: (A) WAXS of PCL and PEG and (B) WAXS of PCL-PEG blends. 
Table 1: Tensile properties of PCL-PEG blends.

\begin{tabular}{|c|c|c|c|}
\hline Blend & $\begin{array}{c}\text { Stress at Break } \\
\text { (MPa) }\end{array}$ & $\begin{array}{c}\text { \% Elongation at } \\
\text { Break }\end{array}$ & $\begin{array}{c}\text { Young's Modulus } \\
\text { (MPa) }\end{array}$ \\
\hline PCL & 32 & 783 & 373 \\
\hline $5 \%$ PEG & 32 & 810 & 412 \\
\hline $5 \%$ PEG-5\%NA & 26 & 572 & 394 \\
\hline 25\% PEG- & 18 & 517 & 453 \\
\hline $5 \% \mathrm{NA}$ & & & \\
\hline
\end{tabular}

Table 2: Transition temperatures and modulus for PCL-PEG blends

Storage Modulus

\begin{tabular}{|c|c|c|c|c|c|}
\hline$\%$ PEG & $\boldsymbol{\beta}\left({ }^{\circ} \mathbf{C}\right)$ & $\alpha\left({ }^{\circ} \mathbf{C}\right)$ & $\operatorname{Tg}\left({ }^{\circ} \mathrm{C}\right)$ & $\log \mathrm{E}^{\prime}$ & (MPa) $23^{\circ} \mathrm{C}$ \\
\hline PCL & -76 & -40 & -55 & 8.45 & 302 \\
\hline $5 \%$ PEG & -75 & -37 & -51 & 8.55 & 357 \\
\hline 5\%PEG-5\%NA & -75 & -36 & -52 & 8.55 & 354 \\
\hline $25 \%$ PEG-5\%NA & -75 & -34 & -50 & 8.64 & 441 \\
\hline
\end{tabular}


Table 3: Melting properties of the PCL-PEG blends at $2^{\circ} \mathrm{C} / \mathrm{min}$.

\begin{tabular}{|c|c|c|c|c|c|c|}
\hline$\%$ PEG & $\operatorname{Tm}\left({ }^{\circ} \mathbf{C}\right)$ & $\begin{array}{c}\Delta \mathrm{Hm} \text { obs } \\
(\mathrm{J} / \mathrm{g})\end{array}$ & $\begin{array}{c}\Delta \mathrm{Hm} \\
\text { theor }(\mathrm{J} / \mathrm{g})\end{array}$ & $\begin{array}{l}\text { Width } \\
(\operatorname{deg} C)\end{array}$ & $\operatorname{Tc}\left({ }^{\circ} \mathbf{C}\right)$ & $\begin{array}{c}\text { Shape of } \\
\text { melt }\end{array}$ \\
\hline $\mathbf{0}$ & 62.4 & 79.7 & - & 5.8 & 33.3 & $\mathrm{R}$ \\
\hline 5 & 62.2 & 82.3 & 86.6 & 4.4 & 34.0 & $\mathrm{R}$ \\
\hline $5-5 \% \mathrm{NA}$ & 62.1 & 93.0 & 103.3 & 5.1 & 37.5 & M \\
\hline $25-5 \% \mathrm{NA}$ & 61.3 & 87.7 & 117.0 & 4.8 & 36.8 & M \\
\hline 100 & 63.9 & 177.3 & - & 2.3 & 43.1 & $\mathrm{R}$ \\
\hline
\end{tabular}

Table 4: Melting properties of the PCL-PEG blends at 100degC/min.

\begin{tabular}{lcccccc}
\hline & & $\mathbf{\Delta H m}$ obs & Width & & & Shape of \\
\%PEG & $\mathbf{T m}\left({ }^{\circ} \mathbf{C}\right)$ & $(\mathbf{J} / \mathbf{g})$ & $(\mathbf{d e g})$ & $\mathbf{T c}\left({ }^{\circ} \mathbf{C}\right)$ & $\mathbf{T c}_{2}\left({ }^{\circ} \mathbf{C}\right)$ & melt \\
\hline $\mathbf{0}$ & 80.1 & 70.8 & 28.5 & 22.3 & - & $\mathrm{R}$ \\
$\mathbf{5}$ & 74.0 & 62.5 & 26.8 & 22.9 & -3.7 & $\mathrm{R}$ \\
$\mathbf{5 - 5 \%} \mathbf{N A}$ & 70.2 & 53.6 & 14.1 & 22.5 & -0.9 & $\mathrm{M}$ \\
$\mathbf{2 5 - 5 \%} \mathbf{N A}$ & 70.6 & 90.6 & 24.3 & 22.4 & -18.1 & $\mathrm{M}$ \\
$\mathbf{1 0 0}$ & 62.9 & 122.8 & 7.3 & 33.69 & - & $\mathrm{R}$ \\
\hline
\end{tabular}


Table 5: Isothermal analysis for PCL-NA blends.

\begin{tabular}{|c|c|c|c|c|}
\hline \%PEG & $\Delta \mathbf{H}(\mathrm{J} / \mathrm{g})$ & $\mathbf{t}$ (mins) & $\mathbf{t}_{1 / 2}(\operatorname{mins})$ & Rate $\left(\mathrm{Jg}^{-1} \mathrm{~min}^{-1}\right)$ \\
\hline 0 & 32.5 & 1.7 & 0.9 & 18.2 \\
\hline 5 & 18.6 & 1.0 & 0.45 & 20.7 \\
\hline $5 \%-5 \% \mathrm{NA}$ & 29.5 & 1.1 & 0.58 & 25.5 \\
\hline $25 \%-5 \% \mathrm{NA}$ & 16.9 & 1.2 & 0.62 & 11.1 \\
\hline
\end{tabular}

Table 6: Decomposition data for PCL-PEG blends.

\begin{tabular}{lc}
\hline \multicolumn{1}{c}{ Decomposition temp $\left({ }^{\circ} \mathrm{C}\right)$} \\
fPEG & for PCL \\
\hline $\mathbf{0}$ & 405 \\
$\mathbf{5}$ & 398 \\
$\mathbf{5 \%}-\mathbf{5 \%} \mathrm{NA}$ & 403 \\
$\mathbf{2 5 \%}-\mathbf{5 \% N A}$ & 390 \\
$\mathbf{1 0 0}$ & 370 \\
\hline
\end{tabular}

